\title{
Experiences of online exposure-based treatment with parental support for teenagers with excessive worry
}

\author{
Tove Wahlund $^{1,2 * *}$ (D), Michaela Wallhem ${ }^{3}$, Eva Serlachius ${ }^{1,2}$ and Hedvig Engberg ${ }^{4,5}$ \\ ${ }^{1}$ Centre for Psychiatry Research, Department of Clinical Neuroscience, Karolinska Institutet, Stockholm, Sweden, ${ }^{2}$ Stockholm \\ Health Care Services, Region Stockholm, CAP Research Centre, Gävlegatan 22, SE-113 30, Stockholm, Sweden, ${ }^{3}$ PRIMA Barn- \\ och Vuxenpsykiatri AB, Stockholm, Sweden, ${ }^{4}$ Department of Women's and Children's Health, Karolinska Institutet, \\ Stockholm, Sweden and ${ }^{5}$ Department of Obstetrics and Gynecology, Karolinska University Hospital, Stockholm, Sweden \\ ${ }^{\star}$ Corresponding author. Email: tove.wahlund@ki.se
}

(Received 28 February 2020; revised 2 October 2020; accepted 21 December 2020)

\begin{abstract}
Worry is a common symptom that can become excessive and is related to several negative health outcomes. Our research group recently developed an online treatment for teenagers with excessive worry with a parallel programme for their parents. The treatment is characterized by a specific focus on exposure to uncertainty and other avoided stimuli, and includes a substantial amount of parental involvement. The aim of this study was to explore how teenagers and their parents experienced the treatment, especially how they perceived working independently with exposure tasks, parental involvement in the treatment programme, and a fixed treatment format. An experienced, independent clinical psychologist interviewed eight teenagers and nine parents in total. The verbatim transcripts were analysed with thematic analysis and two main themes emerged: 'Seeing the worry in a new light' and 'Changing within a set format', which both consisted of three subthemes. Based on the analysis, we concluded that teenagers can work actively with exposure and experience it as helpful even though it can be difficult and strange at first, and that parental involvement can be perceived as beneficial by both teenagers and their parents. While the online format placed a substantial responsibility on the families, and some would have wanted additional therapist support, working independently with one's difficulties was acceptable.
\end{abstract}

\section{Key learning aims}

(1) To learn about experienced benefits and obstacles of exposure in the treatment of worry.

(2) To learn about teenagers' experiences of working independently with exposure.

(3) To consider the impact of parental involvement in psychological treatments for teenagers.

(4) To consider pros and cons of online treatment for teenagers and their parents.

(5) To consider the use of qualitative research approaches to inform further development of psychological treatments for teenagers with excessive worry.

Keywords: exposure; online therapy; parental involvement; qualitative methods; worry

\section{Introduction}

Worry, 'a chain of thoughts and images, negatively affect-laden and relatively uncontrollable' (Borkovec et al., 1983; p 10) is a common psychological phenomenon through the lifespan (Gonçalves and Byrne, 2013; Muris et al., 1998). While worrying also occurs in younger children, it increases in frequency during adolescence (Caes et al., 2015; Muris et al., 2002). For some teenagers, it becomes excessive and is associated with anxiety and depression or the 
development of other psychiatric disorders (Anniko et al., 2018; Boersma et al., 2016; Burstein et al., 2014). Worry is a common symptom in several anxiety disorders, and is the hallmark symptom of generalized anxiety disorder (GAD) [Diagnostic and Statistical Manual of Mental Disorders (DSM-5); American Psychiatric Association, 2013].

Clinical interventions for teenagers with excessive worry have received increased research attention in recent years. Several of these interventions have been based on the intolerance of uncertainty model of worry (Dugas et al., 1998), and have included a number of components such as worry awareness training, exposure to uncertainty through behavioural experiments, challenging of positive beliefs about worry, problem solving, and imaginary exposure. Pilot trials of these interventions have shown promising results (Payne et al., 2011; Perrin et al., 2019; Wahlund et al., 2020a).

Based in this body of work and our clinical experiences, our research group recently developed an online treatment programme (BIP Worry) for teenagers with excessive worry. BIP Worry is a mainly written treatment programme, administered online with limited therapist support. Although BIP Worry is similar to the treatments mentioned above, there are also some important differences. With the aim of 'streamlining' BIP Worry and making it more easily administered online as well as maximally effective, we reduced the number of treatment components and focused specifically on exposure to uncertainty. Furthermore, BIP Worry places a significant focus on involving the parents or legal guardians (hereinafter referred to only as parents) of teenagers with excessive worry in treatment. The programme consists of two independent treatment tracks with ten online treatment modules for the teenagers, and ten parallel modules for their parents.

We pilot-tested BIP Worry in a small study with 13 participants with encouraging results (Wahlund et al., 2020b). The pilot study showed that the treatment was feasible and potentially effective in reducing worry and related anxiety symptoms, but working with the teenagers and their parents in treatment elicited several additional questions for the research group.

First, how did the families engage with exposure? Exposure to feared and avoided stimuli, the main treatment component of BIP Worry, is an effective treatment technique for youth with anxiety disorders including GAD and worry (Whiteside et al., 2019). However, it is still common for clinicians to avoid providing exposure in therapy because of beliefs that it is not sufficiently safe or tolerable for youth (Reid et al., 2018; Whiteside et al., 2016). Interestingly, how teenagers and their parents experience working with exposure in treatment has received relatively little research attention.

Second, how did teenagers and parents experience parental involvement (or lack thereof) in the treatment? Parental behaviours such as control, anxious rearing and rejection have been suggested to play a role in the development and maintenance of anxiety and worry in youth (Chorpita and Barlow, 1998; Waite et al., 2014). Thus, one conclusion may be that modifying parental behaviours could have an impact on anxiety and worry in youth, but the evidence for this not clear (Taboas et al., 2015). Previous meta-analyses of traditional face-to-face treatments point to parental involvement not improving clinical outcomes (Breinholst et al., 2012; Thulin et al., 2014). Parent-supported online interventions on the other hand, have been shown to produce larger effect sizes than interventions without parental support (Grist et al., 2019). How to include parents in the treatment of young people in ways that improve clinical outcomes has been suggested as a future research area (Taboas et al., 2015).

Third, how did teenagers and their parents feel about the fixed treatment format? Scalable online interventions have been suggested to increase the outreach of psychological treatments for symptoms such as excessive worry (Holmes et al., 2018; Kazdin, 2017), and online treatments have been developed for several clinical presentations within child and adolescent mental healthcare with promising treatment outcomes (Grist et al., 2019; Vigerland et al., 2016). While previous qualitative studies have suggested that the online treatment format can be acceptable to teenagers and their parents (McCashin et al., 2019), little is still known about how teenagers and their parents experience working with a fixed treatment format without individual tailoring and with limited therapist support. 
In short, highlighting teenagers' and parents' perspectives on these questions could be valuable for treatment development and implementation, and for clinical practice (McCashin et al., 2019). As a step in that direction, the aim of the present study was to explore how teenagers and their parents experienced exposure, parental involvement in the treatment, and working with a 'set' online treatment structure.

\section{Method}

\section{Informants}

Informants were teenagers and their parents who had participated in a pilot feasibility study of online CBT for adolescents with excessive worry, BIP Worry (Wahlund et al., 2020b). To be included in BIP Worry, teenagers had to score $\geq 30$ on the Penn State Worry Questionnaire for Children (PSWQ-C) (Chorpita et al., 1997) and fulfil criteria for GAD (DSM-5; American Psychiatric Association, 2013). Three to five months after having completed the intervention, all teenagers $(N=12)$ and parents $(N=13)$ were sent an invitation letter describing the interview study. They were subsequently contacted by telephone to ask if they wanted to participate. The teenagers $(n=4)$ and parents $(n=4)$ who declined participation did so due to living too far from the clinic or lack of time. Prior to the interviews, each informant was informed verbally about the aim of the study and that all data would be anonymous, and each was given the opportunity to ask questions about participation, and signed a consent form. Informants received a movie ticket as compensation. The study was approved by the regional ethical review board and is presented in accordance with the COREQ standard (Tong et al., 2007), a reporting standard for qualitative research.

\section{The intervention}

The BIP Worry intervention lasted for 10 weeks and was provided via a secure internet platform. It included two independent treatment tracks, one for the teenagers and one for the parents. Each track consisted of ten treatment modules (similar to chapters in a book). Table 1 presents the main content of each module for the teenagers and the parents, respectively. The treatment content was predetermined (fixed) without any individual tailoring, and consisted mainly of texts, video clips, illustrations and worksheets that the participants filled in. (For more detailed information about the intervention, see Wahlund et al., 2020b.)

During the treatment, both teenagers and their parents had access to a designated psychologist. Individual support from the psychologist was provided in written form via the internet treatment platform, and telephone calls could be scheduled upon request. The psychologist's role was to help the families put the treatment content into practice (e.g. coming up with relevant exposure exercises) and to provide emotional support when needed. The psychologist could also answer questions, clarify treatment rationale, and help solve problems related to the intervention. At least twice a week, the psychologist read what the teenagers and parents had written in the platform, and provided encouragement for having worked with the treatment. Both teenagers and their parents were encouraged to reach out to the psychologist in case of any questions or concerns about the treatment. If the teenagers or parents were not active in treatment for a period of time, the psychologist contacted them for problem solving.

In the pilot study, the psychologists spent on average 21 minutes per week writing to each family (one teenager and one parent), i.e. therapist support was limited (Wahlund et al., 2020b).

\section{The interviews}

Interviews $(n=16)$ were conducted from October 2018 to January 2019 by the second author. The interviews were scheduled at the informants' earliest convenience after having been invited to the 
Table 1. Overview of the BIP Worry intervention

\begin{tabular}{|c|c|c|}
\hline Module & Teenagers' content & Parents' content \\
\hline 1 & Psychoeducation on worry & Psychoeducation on worry \\
\hline 2 & Worry behaviours & Worry behaviours \\
\hline \multirow[t]{2}{*}{3} & Introduction to exposure, setting goals for treatment & Exposure \\
\hline & & Common parental reactions to worry \\
\hline \multirow[t]{2}{*}{4} & Exposure to thoughts & Exposure to thoughts \\
\hline & & Alternative parental strategies \\
\hline \multirow[t]{2}{*}{5} & Being proactive when facing uncertainty & Being proactive \\
\hline & & More alternative strategies for parents \\
\hline 6 & Making decisions related to worry and uncertainty & $\begin{array}{l}\text { Making decisions related to worry and uncertainty } \\
\text { Adolescent development related to worry }\end{array}$ \\
\hline 7 & How to let go of control behaviours & Being supportive as a parent \\
\hline 8 & Summary so far, evaluating goals & Summary so far \\
\hline 9 & Relapse prevention & Relapse prevention \\
\hline 10 & Planning for the future & Planning for the future \\
\hline
\end{tabular}

study, and occurred 5 to 7 months $($ mean $=6)$ after they had completed the intervention. The interviewer is a clinical psychologist with experience in treating patients with excessive worry in a traditional face-to-face format, but she was not involved in the pilot study (Wahlund et al., 2020b). Two semi-structured interview guides (one for the teenagers and one for the parents) were developed by the first and second author and reviewed by the last author. The guides were based on the perceived knowledge gaps identified when working with the pilot study (Wahlund et al., 2020b), previous research (McCashin et al., 2019) and clinical experience. The interview guides were thoroughly discussed until agreement was reached in the research team. The final versions were subsequently pilot tested during the first two interviews. No changes resulted from the pilot testing, and the guides were used for all interviews.

The teenagers $(n=8)$ and the parents $(n=9)$ were interviewed separately. The teenagers were between 14 and 18 years old (mean $=16.2, S D=1.6$ ). All but one were girls. Of the parents, six were women and three were men. In one case, both parents participated in the treatment and those parents were interviewed together. The informants chose the place of the interview (two at the clinic and 15 in the informants' homes). The interviews lasted for 30 to 60 minutes (mean $=43.1, S D=9.0$ ) and were terminated when the informants conveyed that they did not have more to say. All interviews were audio taped and transcribed verbatim.

\section{Analysis}

The interviews were analysed using thematic analysis (Braun and Clarke, 2006), a qualitative method with the aim of identifying themes throughout data. The thematic analyses followed the steps outlined in Table 2. All written transcripts were read through several times for the research group to become acquainted with the data. The process includes inductive coding followed by grouping through constant comparison. The first six interviews were coded together by the first, second and last author to reach consensus in the coding. The second author then read, coded and grouped the rest of the transcripts with parallel discussions in the research group. The themes were created iteratively. The research team worked together during the process in order to ensure trustworthiness. To achieve optimal credibility and transferability, themes were compared and modified to eliminate redundancies. Throughout the process, identified themes were tested against the transcribed interviews by the authors and even though it is described as a linear process, it was a back-and-forth movement between the steps outlined by Braun and Clarke (2006). The themes were defined to maximize outer diversity and inner agreement. The analytic process was repeated until no new themes were identified and consensus was reached in the research group, and then the 
Table 2. Six-step thematic analysis procedure as described by Braun and Clarke (2006)

\begin{tabular}{|c|c|c|}
\hline Analytic step & Description & Example from the analysis \\
\hline Familiarizing & $\begin{array}{l}\text { Reading the transcribed } \\
\text { interviews multiple times } \\
\text { and noting reflections }\end{array}$ & $\begin{array}{l}\text { Reflections } \\
\text { Parents have a lot of thoughts on how their teenager } \\
\text { experienced the treatment } \\
\text { Teenagers talk about their own experience }\end{array}$ \\
\hline Coding & $\begin{array}{l}\text { Applying initial codes to } \\
\text { data relevant to the } \\
\text { research question }\end{array}$ & $\begin{array}{l}\text { 'It was, well because the treatment should work for so } \\
\text { many people, then I think everyone who goes through } \\
\text { the treatment has to, well you have to make some small } \\
\text { adjustments' was coded as 'Receiving standardized } \\
\text { treatment' }\end{array}$ \\
\hline Searching for themes & $\begin{array}{l}\text { Grouping the codes into } \\
\text { potential themes } \\
\text { Assembling all data rele- } \\
\text { vant to each potential } \\
\text { theme }\end{array}$ & $\begin{array}{l}\text { Temporary subtheme: 'Understanding oneself and feeling } \\
\quad \text { understood' } \\
\text { Example of codes added: } \\
\text { - Understanding oneself } \\
\text { - Feeling less lonely } \\
\text { - Recognition in treatment personas }\end{array}$ \\
\hline Reviewing and revising & $\begin{array}{l}\text { Checking whether the sub- } \\
\text { themes and themes work } \\
\text { in relation to their codes } \\
\text { and to all relevant data }\end{array}$ & $\begin{array}{l}\text { Merging subthemes: } \\
\text { The subtheme 'Working with the online treatment was } \\
\text { twofold' was merged into 'Freedom with responsibility', } \\
\text { which increased inner homogeneity and outer heteroge- } \\
\text { neity }\end{array}$ \\
\hline Defining and renaming & $\begin{array}{l}\text { Define the specifics for each } \\
\text { theme and generate clear } \\
\text { definitions and names for } \\
\text { all themes }\end{array}$ & $\begin{array}{l}\text { Renaming through team consensus: } \\
\text { Theme 'Reframing' was clarified as 'Seeing the worry in a } \\
\text { new light' }\end{array}$ \\
\hline Writing the manuscript & $\begin{array}{l}\text { Final opportunity for } \\
\text { analysis, finding quotes to } \\
\text { enhance data }\end{array}$ & $\begin{array}{l}\text { Quotes were added to show how well the data, } \\
\text { subthemes and themes match } \\
\text { 'So it has, I do think that it has given my and X's } \\
\text { relationship a good push or how to put it' was added to } \\
\text { the subtheme 'Collaboration between the teenagers } \\
\text { and their parents' }\end{array}$ \\
\hline
\end{tabular}

themes were labelled. All themes are illustrated with original quotes from the transcripts to ensure transferability. The interviews were conducted in Swedish and a native English speaker has confirmed the appropriateness of the translated quotes.

\section{Results}

Two main themes were identified in the data: (1) Seeing the worry in a new light, and (2) Changing within a set format. An overview of themes and subthemes are presented in Table 3. The themes followed by subthemes, and quotes are presented below. Quotes are attributed to individual informants $(\mathrm{P}=$ Parent, $\mathrm{T}=$ Teenager $)$.

\section{Theme 1: Seeing the worry in a new light}

Theme 1, 'Seeing the worry in a new light' summarizes experiences of how the treatment influenced the teenagers' and parents' views on worry, worry-related behaviours, and parenting in relation to worry. The three subthemes are described and illustrated with quotes below.

\section{Theme 1, subtheme 1: Understanding oneself and feeling understood}

Most teenagers and parents described that recognizing themselves (as a teenager or a parent) in the written treatment material was a positive experience. ' . . . /you sort of knew already that you're 
Table 3. Themes and subthemes identified in the data

\begin{tabular}{lll}
\hline Theme level & Name of theme/subtheme \\
\hline $\begin{array}{l}\text { Themes } \\
\text { Subthemes }\end{array}$ & $\begin{array}{c}\text { Seeing the worry in a new light } \\
\text { Understanding oneself and feeling } \\
\text { understood } \\
\text { Changing behaviours in relation to } \\
\text { worry } \\
\text { Parenting a worried teenager }\end{array}$ & $\begin{array}{c}\text { Changing within a set format } \\
\text { A fixed treatment format with limited therapist } \\
\text { support } \\
\text { Freedom with responsibility }\end{array}$ \\
& $\begin{array}{c}\text { Collaboration between the teenagers and their } \\
\text { parents }\end{array}$ \\
\hline
\end{tabular}

not alone, but when there were such concrete things that were true for you, you felt like "it really isn't just me".' (T6)

The teenagers expressed that they understood their own worry and anxiety better after having worked with BIP Worry. There was a greater sense of acceptance of themselves and the challenges they faced (such as worry, anxiety, the concept of death, and that some things in life are not perfect) after the treatment: 'Now I've been able to understand my anxiety and stuff. Or I've understood like, what leads to what. And then I've been able to handle it better.' (T7)

Parents could also understand their teenagers better after treatment. Some indicated that it had been an eye-opening experience to listen to the teenager talk about their worry: 'I probably didn't understand that it was, that she [the teenager] had such a hard time because she didn't show it at home ... And once we started talking more, then we understood.' (P6)

\section{Theme 1, subtheme 2: Changing behaviours in relation to worry}

Working independently with one's excessive worry was a positive experience for many teenagers. Additionally, some parents described it as a lifted burden of responsibility for them when their teenagers learned to deal with difficult emotions themselves: " .../it gave her [the teenager] strength that she herself came up with the solutions. And the ideas of how she would go forward.' (P1)

A common experience was that behaviour change (e.g. exposure, reducing parental accommodation to worry) initially felt difficult, unnatural or weird, and some exposures were avoided because they were perceived as too scary or unpleasant. However, doing exposures could also make teenagers feel brave and proud of themselves, and the more exposures they did, the easier it got. Exposing themselves to situations and thoughts they would normally avoid and letting go of control behaviours felt beneficial in reducing worry: 'Well it was hard then. But since it didn't take many times before you noticed it was getting easier, and I guess that was a bit motivating. So it was hard work but it became obvious quite quickly that it paid off.' (T8)

\section{Theme 1, subtheme 3: Parenting a worried teenager}

The treatment provided an opportunity for some parents to reflect on how they responded to their teenagers' worrying: 'I became aware of how I might be behaving, and what I was saying and doing to comfort or facilitate, but that might instead make it worse. I think it was good to become aware of that and be a part of the treatment.' (P3)

Some employed new strategies in the immediate face of excessive worry and experienced that this had an impact on their interaction with the teenager. They learned to take a step back and listen more, and that could help move the family forward instead of getting stuck in worry, frustration or reassurances: 'Yes, it [the relationship] got less, what is it called? Less strained. So it became less stressful. Because she [the parent] could handle it better when I was irritated.' (T3) 
However, some parents did not think they had any impact on their teenager's excessive worrying: 'I don't think that my behaviour has changed that much though. /.../I don't really think that we, that her worry and anxiety ... like, the root of the problem is not us parents really.' (P2)

\section{Theme 2: Changing within a set format}

Theme 2, 'Changing within a set format', describes the experiences of working with a set online treatment with limited therapist support. The three subthemes are described below.

\section{Theme 2, subtheme 1: A fixed treatment format with limited therapist support}

Even though many informants described the treatment content as relevant to them, example characters in the programme could be perceived as exaggerated, and specific treatment components were sometimes experienced as irrelevant. Most parents accepted that the programme was fixed beforehand and did not fit everyone perfectly. They could actively choose to work more with treatment components that felt relevant to them and their teenager. Many teenagers also found the fixed format acceptable, but the irrelevancies led to frustration for others: 'I felt that I, as middle-aged and an academic, had no problem making these transfers and seeing how it might fit. But, that was very difficult for $X$ [the teenager]. In other words, if it didn't describe things exactly as she is, "then it doesn't apply to me".' (P4)

Both teenagers and parents thought that having met the psychologist before the online treatment began was helpful. During treatment, several reached out to the psychologists when facing difficulties, and they got feedback that felt personal and motivating: 'Obviously, it's a bit generic. But at the same time, you also got pretty frequent feedback e-mails. So I mean, then you got a personal touch on it as well.' (P2)

However, there was also an experience that the responses from the psychologists were too short or lacked substance, and some informants found it difficult to express themselves in writing. They believed that more physical meetings or telephone calls with the psychologist would have led to more candid conversations and better individual tailoring of the treatment. Some did not reach out to their designated psychologist or were not honest with how much they were working with the treatment. For the teenagers, one obstacle to get help from the psychologist was that they did not dare to ask twice when they faced difficulties: 'If I, for example, had a question about a task and she [the psychologist] explained in a way I didn't understand, then maybe she could have asked if she could call me and talk about it. That might have made it easier.' (T1)

\section{Theme 2, subtheme 2: Freedom with responsibility}

Many parents conveyed that they thought that their teenager's symptoms were not severe enough to warrant face-to-face treatment (even though all teenagers fulfilled criteria for GAD and scored high on a measure of excessive worry pre-treatment), and that the online format therefore suited them especially well. Other benefits to the online format that were mentioned were not having to take time off school or work to attend physical sessions, and that the written format facilitated learning because they could access the treatment at all times: '...$/$ I think it would have been very difficult to get us to do a joint treatment for twelve weeks together. Now we could do it even though we are a family that doesn't have a lot of time.' (P1)

Even though the participants appreciated the freedom of an online treatment, both teenagers and their parents described that the teenagers sometimes forgot both to practise behaviour change (e.g. exposure to uncertainty), and to log on to the treatment platform and report on their progress: ' $\% /$ II guess it [the online treatment] was convenient, but it became a bit like, sometimes you forget it and then it becomes stressful when you sit there and haven't done it, you know.' (T5) 
Parents found that the teenagers' general state of mind and motivation could affect how much they worked with the programme. Some indicated that periods of less worry led to lower motivation, and others found that a depressive mood or more worry decreased engagement. Parents described that there was little they could do to increase their teenagers' motivation: $\%$... /and I think that was also more towards the end of the treatment when $X$ [the teenager] also started to feel better and it was like, then it felt a little too ambitious. /... P (P1)

For parents, it could be difficult to fit the treatment into already busy schedules, or they postponed treatment or did less than they had intended because they found it challenging. Several parents expressed a need for more support with structuring their work: 'But it's probably like, just having some kind of schedule, or it doesn't have to be a schedule, but some kind of to-do list would have been good /... P (P7)

Theme 2, subtheme 3: Collaboration between the teenagers and their parents

Some teenagers worked closely with their parents through the treatment. The parents reminded them to log into the platform and to conduct exposures, and they discussed the treatment content. Some families had always had a strong relationship and felt that collaboration during the treatment came naturally. Both teenagers and parents who worked closely together felt that the treatment would have been more difficult or not possible without support from a parent: 'It was good because then afterwards, if we had done the task, then she [the parent] could remind me during the week, "yes, but remember to do this". So she pushed me a little as well, in a good way. To get me to do the exposure ...' (T3)

While parents appreciated playing an active role in the treatment, the involvement could also be burdensome: 'But it can be a bit hard to feel that you are the one who has to push this through. I went with my gut feeling that $X$ [the teenager] would think it [the treatment] was a good thing to have done once she had done it. But if I hadn't believed so hard in it, then I would've given up on a number of occasions.' (P4)

Other families did not collaborate as much. Some parents expressed that collaboration and behaviour change was difficult to achieve because the two independent treatment tracks did not force them to collaborate. Some teenagers appreciated that they could choose the level of collaboration, but a few would have appreciated more involvement from their parents: 'We [the teenager and the parent] did not talk very much about each other's [programme] so it was a bit confusing because I did not know if they did the same thing that I did or what they did. /.../At first, I thought the intention was that we would like, that our programs would be linked together in some way, but they weren't.' (T2)

After the intervention, some teenagers and some parents perceived improvement in their relationship, especially for those who described their relationships as close before the treatment: 'So it has, I do think that it has given my and X's relationship a good push or however you want to put it.' (P5)

\section{Discussion}

This qualitative study conveys the experiences of eight teenagers and nine parents who participated in a fixed online treatment with two independent treatment tracks, one for the teenagers with excessive worry and one for their parents.

The findings showed that working with behaviour change, especially through exposure to uncertainty and other avoided stimuli, was perceived as challenging, especially at first. Exposing oneself to situations that were perceived as uncertain or scary, and which the teenagers would normally avoid, could initially be perceived as strange or unnatural. Several also described avoiding exposures that were perceived as too difficult. However, many 
teenagers also experienced quick positive effects of the exposures once they did engage with them. This indicates that clinicians have an important role to play in identifying obstacles to exposure. If clinicians can help their patients overcome the first impression of exposure to uncertainty as weird, unfamiliar or too difficult, the findings suggest that teenagers can benefit from the intervention quickly.

Both teenagers and parents highlighted the perceived importance of parental involvement for the teenagers' treatment adherence. Parents appreciated being involved in treatment, as it helped them understand their teenager's worry, develop new ways of supporting their teenager, and deal with short-term negative effects of the intervention. These experiences are in contrast with the conclusions drawn in several meta-analyses of traditional face-toface treatments of anxiety disorders in youth, including GAD and excessive worry, which state that parental involvement does not improve clinical outcomes (Breinholst et al., 2012; Thulin et al., 2014). Another meta-analysis has shown that parental involvement can improve outcomes in online intervetions for youth (Grist et al., 2019), and it may be that parents are especially important in online treatments where the young patient does not have the same support from a therapist as in face-to-face therapy. However, there may be a role for parents in both face-to-face and online treatments for teenagers that still needs to be explored further (Taboas et al., 2015).

Some parents and teenagers described that the intervention had helped improve their relationship. Previous research has found that parental rejection and over-protection is associated with worry and GAD in adulthood (Beesdo et al., 2010). Whether improvements in teenager-parent relationships after treatment also correlate with better long-term treatment outcomes could be a topic for future studies.

In accordance with previous research of experiences of online CBT (McCashin et al., 2019), several teenagers highlighted that being able to relate to the fictional characters in the BIP Worry programme was helpful, and that the online format helped them transfer what they learned in treatment to their everyday lives in a flexible way. While the online treatment was experienced as convenient, it also placed a burden of responsibility on both the teenagers and their parents. Previous research on experiences of internet-delivered treatments has found that some patients appreciate working independently, while others would have preferred face-toface meetings (Bendelin et al., 2011; Halmetoja et al., 2014). It has also been noted that the treatment material in online CBT can be too broad to be relevant for some individuals (McCashin et al., 2019). A slightly different picture emerged in the present study where many informants would not have preferred face-to-face over online treatment even though they had experienced some negative aspects of BIP Worry. Many would have appreciated some additional contact with their therapist, without wanting a traditional face-to-face treatment. How more therapist support could be included in online treatments in terms of frequency and method (e.g. meeting in person, telephone calls, or additional online messages), and its effects on treatment outcomes, could be questions for further research. Furthermore, we may not only need to identify those for whom online treatment is best suited, but also find ways of informing patients about the potential pros and cons of the online format in order to adjust expectations of the treatment.

Both teenagers and parents described that the teenager's state of mind (e.g. feeling more depressed or less worried) had an impact on their experienced motivation to work with the treatment programme. These findings could be interpreted as showing a need for more individual tailoring in online treatments to increase adherence (e.g. different tracks that the patients can choose between depending on their state of mind). Interestingly, both the teenagers and their parents completed almost all of the treatment modules and many reported working actively with the interventions (Wahlund et al., 2020b). Thus, it could be that the experience of motivation fluctuated during the treatment period without having an impact on the actual adherence. 


\section{Strengths and limitations}

Although our study provides important insights into how exposure, parental involvement and a structured (fixed) treatment format can be experienced by teenagers and their parents in Sweden, it also has limitations.

First, in order not to interfere with the 3-month follow-up assessments in the pilot study of BIP Worry (Wahlund et al., 2020b), we invited the families to this qualitative study soon after the follow-up assessments. For several families that time point coincided with the summer holidays, and in those cases we waited to invite them until school started in order to increase participation. This meant that there was a considerable time lag (5 to 7 months) between completing treatment and participating in the qualitative interviews. Thus, the data reflect the informants' experiences in the 'rear view mirror' rather than during the actual intervention and the risk for recall bias has to be taken into account when considering the findings.

Second, in qualitative methods, data are inherently subjective and represent the unique experience of the participants (Charmaz, 2006). Sample recruitment from a single pilot study means that the findings are limited to these teenagers, their parents, and their context. However, the variety of experiences on the part of the teenagers and parents coupled with a research team with varying perspectives contributed to a richer understanding of the data.

Third, qualitative research is sensitive to interviewer and analyst bias. In order not to overwhelm the informants (who had already participated in the pilot study with frequent selfreport measures over a number of months), we did not ask for their feedback on the transcribed interviews or our final conclusions. Instead, credibility was improved through analyst triangulation performed throughout the analysis to ensure coding consistency, and by checking interpretations against the data. Furthermore, the interviewer (the second author) is an experienced clinical psychologist who was not previously involved in designing the BIP Worry programme, nor the data collection process or treatment in the pilot study. The research team consisted of a varied group of individuals, representing different research communities, and everyone was involved in discussions surrounding the coding, interpretation of the data, dialogues on how to judge similarities and differences in the data, and how to avoid pre-conceptions. For the reader to be able to judge the credibility of our conclusions, the entire analytical process is described in detail and quotes are added to the description of the findings, as this also encompasses how well the data, subthemes and themes match.

\section{Conclusions}

In conclusion, the findings from this qualitative study highlight experiences of an online exposurebased treatment for teenagers with excessive worry, and their parents. Teenagers could work independently with exposure, and experience it as helpful. While exposure and other types of behaviour change could be challenging, most informants found the treatment rationale reasonable. The treatment format allowed for a substantial amount of parental involvement, and some teenagers and parents perceived this as essential to treatment adherence. For those who did not collaborate as much, the parallel treatment track for parents did not appear to be harmful. The online format placed substantial responsibility on the teenagers and their parents, and some would have preferred more therapist support. However, working independently with one's difficulties could also be empowering.

Acknowledgements. The authors wish to thank the participating teenagers and parents for sharing their experiences and making the study possible.

Financial support. This work was supported by the Swedish Research Council for Health, Working Life and Welfare, Forte (grant number 2014-4052); Region Stockholm, HNSV (grant number 14099) (Dr Serlachius, grant number 20170605); and PRIMA Barn- och Vuxenpsykiatri AB (Ms Wallhem). 
Conflict of interest. Dr Wahlund, Ms Wallhem, Dr Engberg and Dr Serlachius have no conflicts of interest with respect to this publication.

Ethical statements. The authors have abided by the by the Ethical Principles of Psychologists and Code of Conduct as set out by the BABCP and BPS. The national ethical review board in Sweden approved the study (registration ID: 2018/1587).

Data availability. The data are not publicly available due to their containing information that could compromise the privacy of the research participants.

Key practice points

(1) An online treatment with a fixed format may be experienced as helpful even though it does not fit everyone perfectly: while several teenagers and parents would have wanted more therapist support, many appreciated the treatment being accessible via the internet and the written communication with the psychologist.

(2) Exposure to anxiety- and worry-inducing situations can initially be perceived as too difficult or strange, but may contribute to worry reductions relatively quickly for those who engage with it.

(3) It may be feasible for teenagers to engage with exposure independently with written support from a psychologist.

(4) Parental involvement was experienced by many as crucial to the teenagers' treatment adherence. How this translates to regular (face-to-face) treatments and in the treatment of other psychological problems should be explored in practice and in future studies.

\section{Further reading}

McCashin, D., Coyle, D., \& O'Reilly, G. (2019). Qualitative synthesis of young people's experiences with technology-assisted cognitive behavioral therapy: systematic review. Journal of Medical Internet Research, 21, e13540.

Reid, A. M., Guzick, A. G., Fernandez, A. G., Deacon, B., McNamara, J. P., Geffken, G. R., . . \& Striley, C. W. (2018). Exposure therapy for youth with anxiety: Utilization rates and predictors of implementation in a sample of practicing clinicians from across the United States. Journal of Anxiety Disorders, 58, 8-17.

Taboas, W. R., McKay, D., Whiteside, S. P. H., \& Storch, E. A. (2015). Parental involvement in youth anxiety treatment: conceptual bases, controversies, and recommendations for intervention. Journal of Anxiety Disorders, 30, 16-18.

Whiteside, S. P., Sim, L. A., Morrow, A. S., Farah, W. H., Hilliker, D. R., Murad, M. H., \& Wang, Z. (2019). A metaanalysis to guide the enhancement of CBT for childhood anxiety: exposure over anxiety management. Clinical Child and Family Psychology Review, 23, 102-121.

\section{References}

American Psychiatric Association (2013). Diagnostic and Statistical Manual of Mental Disorders (5th edn). American Psychiatric Association.

Anniko, M. K., Boersma, K., \& Tillfors, M. (2018). Sources of stress and worry in the development of stress-related mental health problems: a longitudinal investigation from early- to mid-adolescence. Anxiety, Stress, \& Coping, 32, $155-167$. https://doi.org/10.1080/10615806.2018.1549657

Beesdo, K., Pine, D. S., Lieb, R., \& Wittchen, H.-U. (2010). Incidence and risk patterns of anxiety and depressive disorders and categorization of generalized anxiety disorder. Archives of General Psychiatry, 67, 47-57. https://doi.org/10.1001/ archgenpsychiatry.2009.177

Bendelin, N., Hesser, H., Dahl, J., Carlbring, P., Nelson, K. Z., \& Andersson, G. (2011). Experiences of guided Internetbased cognitive-behavioural treatment for depression: a qualitative study. BMC Psychiatry, 11. https://doi.org/10.1186/ 1471-244X-11-107

Boersma, K., Ljótsson, B., Edebol-Carlman, H., Schrooten, M., Linton, S. J., \& Brummer, R. J. (2016). Exposure-based cognitive behavioral therapy for irritable bowel syndrome. A single-case experimental design across 13 subjects. Cognitive Behaviour Therapy, 45, 415-430. https://doi.org/10.1080/16506073.2016.1194455

Borkovec, T. D., Robinson, E., Pruzinsky, T., \& DePree, J. A. (1983). Preliminary exploration of worry: some characteristics and processes. Behaviour Research and Therapy, 21, 9-16. https://doi.org/10.1016/0005-7967(83)90121-3

Braun, V., \& Clarke, V. (2006). Using thematic analysis in psychology. Qualitative Research in Psychology, 3, 77-101. https:// doi.org/10.1191/1478088706qp063oa

Breinholst, S., Esbjørn, B. H., Reinholdt-Dunne, M. L., \& Stallard, P. (2012). CBT for the treatment of child anxiety disorders: a review of why parental involvement has not enhanced outcomes. Journal of Anxiety Disorders, 26, 416-424. https://doi.org/https://doi.org/10.1016/j.janxdis.2011.12.014 
Burstein, M., Beesdo-Baum, K., He, J. P., \& Merikangas, K. R. (2014). Threshold and subthreshold generalized anxiety disorder among US adolescents: prevalence, sociodemographic, and clinical characteristics. Psychological Medicine, 44, 2351-2362. https://doi.org/https://doi.org/10.1017/S0033291713002997

Caes, L., Fisher, E., Clinch, J., Tobias, J. H., \& Eccleston, C. (2015). The development of worry throughout childhood: Avon Longitudinal Study of Parents and Children data. British Journal of Health Psychology, 21, 389-406. https://doi.org/https:// doi.org/10.1111/bjhp.12174

Charmaz, K. (2006). Constructing Grounded Theory: A Practical Guide Through Qualitative Analysis. Sage Publications Ltd. https://doi.org/10.3402/qhw.v1i3.4932

Chorpita, B. F., \& Barlow, D. H. (1998). The development of anxiety: the role of control in the early environment. Psychological Bulletin, 124, 3-21. doi: 10.1037/0033-2909.124.1.3

Chorpita, B. F., Tracey, S. A., Brown, T. A., \& Collica, T. J. (1997). Assessment of worry in children and adolescents: an adaptation of the Penn State Worry Questionnaire. Behaviour Research and Therapy, 35, 569-581. https://doi.org/10.1016/ S0005-7967(96)00116-7

Dugas, M. J., Gagnon, F., Ladouceur, R., \& Freeston, M. H. (1998). Generalized anxiety disorder: a preliminary test of a conceptual model. Behaviour Research and Therapy, 36, 215-226. https://doi.org/10.1016/S0005-7967(97)00070-3

Gonçalves, D. C., \& Byrne, G. J. (2013). Who worries most? Worry prevalence and patterns across the lifespan. International Journal of Geriatric Psychiatry, 28, 41-49. https://doi.org/10.1002/gps.3788

Grist, R., Croker, A., Denne, M., \& Stallard, P. (2019). Technology delivered interventions for depression and anxiety in children and adolescents: a systematic review and meta-analysis. Clinical Child and Family Psychology Review, 22, $147-171$. https://doi.org/10.1007/s10567-018-0271-8

Halmetoja, C. O., Malmquist, A., Carlbring, P., \& Andersson, G. (2014). Experiences of internet-delivered cognitive behavior therapy for social anxiety disorder four years later: a qualitative study. Internet Interventions, 1, $158-163$. https://doi.org/10.1016/j.invent.2014.08.001

Holmes, E. A., Ghaderi, A., Harmer, C. J., Ramchandani, P. G., Cuijpers, P., Morrison, A. P., Roiser, J. P., Bockting, C. L. H., O'Connor, R. C., Shafran, R., Moulds, M. L., \& Craske, M. G. (2018). The Lancet Psychiatry Commission on psychological treatments research in tomorrow's science. The Lancet Psychiatry, 5, 237-286. https://doi.org/10.1016/ S2215-0366(17)30513-8

Kazdin, A. E. (2017). Addressing the treatment gap: a key challenge for extending evidence-based psychosocial interventions. Behaviour Research and Therapy, 88, 7-18. https://doi.org/10.1016/j.brat.2016.06.004

McCashin, D., Coyle, D., \& O'Reilly, G. (2019). Qualitative synthesis of young people's experiences with technology-assisted cognitive behavioral therapy: systematic review. Journal of Medical Internet Research, 21, e13540. https://doi.org/10.2196/ 13540

Muris, P., Meesters, C., Merckelbach, H., Sermon, A., \& Zwakhalen, S. (1998). Worry in normal children. Journal of the American Academy of Child and Adolescent Psychiatry, 37, 703-710. https://doi.org/10.1097/00004583-199807000-00009

Muris, P., Merckelbach, H., Meesters, C., \& van den Brand, K. (2002). Cognitive development and worry in normal children. Cognitive Therapy and Research, 26, 775-787. https://doi.org/10.1023/A:1021241517274

Payne, S., Bolton, D., \& Perrin, S. (2011). A pilot investigation of cognitive therapy for generalized anxiety disorder in children aged 7-17 years. Cognitive Therapy and Research, 35, 171-178. https://doi.org/10.1007/s10608-010-9341-z

Perrin, S., Bevan, D., Payne, S., \& Bolton, D. (2019). GAD-specific cognitive behavioral treatment for children and adolescents: a pilot randomized controlled trial. Cognitive Therapy and Research, 43, 1051-1064. https://doi.org/10. 1007/s10608-019-10020-3

Reid, A. M., Guzick, A. G., Fernandez, A. G., Deacon, B., McNamara, J. P., Geffken, G. R., ... \& Striley, C. W. (2018). Exposure therapy for youth with anxiety: utilization rates and predictors of implementation in a sample of practicing clinicians from across the United States. Journal of Anxiety Disorders, 58, 8-17. https://doi.org/10.1016/j.janxdis.2018.06.002

Taboas, W. R., McKay, D., Whiteside, S. P. H., \& Storch, E. A. (2015). Parental involvement in youth anxiety treatment: conceptual bases, controversies, and recommendations for intervention. Journal of Anxiety Disorders, 30, 16-18. https://doi. org/10.1016/j.janxdis.2014.12.005

Thulin, U., Svirsky, L., Serlachius, E., Andersson, G., \& Öst, L.-G. (2014). The effect of parent involvement in the treatment of anxiety disorders in children: a meta-analysis. Cognitive Behaviour Therapy, 43, 185-200. https://doi.org/https://doi.org/ $10.1080 / 16506073.2014 .923928$

Tong, A., Sainsbury, P., \& Craig, J. (2007). Consolidated criteria for reporting qualitative research (COREQ): a 32-item checklist for interviews and focus groups. International Journal for Quality in Health Care, 19, 349-357. https://doi. org/10.1093/intqhc/mzm042

Vigerland, S., Lenhard, F., Bonnert, M., Lalouni, M., Hedman, E., Ahlen, J., Olén, O., Serlachius, E., \& Ljótsson, B. (2016). Internet-delivered cognitive behavior therapy for children and adolescents: a systematic review and meta-analysis. Clinical Psychology Review, 50, 1-10. https://doi.org/10.1016/j.cpr.2016.09.005

Wahlund, T., Andersson, E., Jolstedt, M., Perrin, S., Vigerland, S., \& Serlachius, E. (2020a). Intolerance of uncertaintyfocused treatment for adolescents with excessive worry: a pilot feasibility study. Cognitive and Behavioral Practice, 27. https://doi.org/10.1016/j.cbpra.2019.06.002 
Wahlund, T., Jolstedt, M., Andersson, E., Vigerland, S., Perrin, S., Öst, L.-G., Högström, J., \& Serlachius, E. (2020b). Online cognitive behavior therapy for adolescents with excessive worry: a multiple baseline design feasibility study. mHealth, 6. https://doi.org/10.21037/mhealth.2019.09.10

Waite, P., Whittington, L., \& Creswell, C. (2014). Parent-child interactions and adolescent anxiety: a systematic review. Psychopathology Review, a1, 51-76. https://doi.org/10.5127/pr.033213

Whiteside, S. P., Deacon, B. J., Benito, K., \& Stewart, E. (2016). Factors associated with practitioners' use of exposure therapy for childhood anxiety disorders. Journal of Anxiety Disorders, 40, 29-36. https://doi.org/10.1016/j.janxdis.2016. 04.001

Whiteside, S. P., Sim, L. A., Morrow, A. S., Farah, W. H., Hilliker, D. R., Murad, M. H., \& Wang, Z. (2019). A metaanalysis to guide the enhancement of CBT for childhood anxiety: exposure over anxiety management. Clinical Child and Family Psychology Review, 23, 102-121. https://doi.org/10.1007/s10567-019-00303-2

Cite this article: Wahlund T, Wallhem M, Serlachius E, and Engberg H. Experiences of online exposure-based treatment with parental support for teenagers with excessive worry. The Cognitive Behaviour Therapist. https://doi.org/10.1017/ S1754470X21000027 